\title{
Aspectos de Biossegurança Com Enfoque em Fonoaudiologia: Revisão de Literatura
}

\section{Aspects of Biosafety with Focus on Speech-Language Pathology: Literature Review}

\author{
Andrea Cintia Laurindo Porto*a; Rayane Justino Gomes; ; Tayná Maríllia da Costa Silvaa; Priscilla Mayara Estrela \\ Barbosa $^{a}$; Caroline Sampaio Sousa ${ }^{\text {a; }}$ Francisca Jakelyne de Farias Marques ${ }^{\mathrm{a}}$
}

${ }^{\mathrm{a} F a c u l d a d e ~ P i t a ́ g o r a s, ~ C E, ~ B r a s i l . ~}$

*E-mail: andreacintialp@gmail.com

\begin{abstract}
Resumo
A Biossegurança é de extrema importância para qualquer tipo de trabalhador na execução de seu ofício. Para os profissionais da saúde, além de proporcionar tal direito ao paciente, as condutas em Biossegurança erradicam as possíveis formas de contaminação cruzada durante os atendimentos. O objetivo deste trabalho é proporcionar o esclarecimento sobre Biossegurança na Fonoaudiologia, sobretudo, para profissionais já atuantes e para auxiliar estudantes da área. A metodologias utilizada foi a revisão de literatura, na base de dados Scielo, Lilacs e Google Acadêmico, com base nos Descritores em Ciência e Saúde: biossegurança, contaminação, fonoaudiologia e saúde. Os critérios de inclusão foram: artigos que abordassem a temática, em português, on-line, na íntegra, publicados de 2007 a 2017 . A Fonoaudiologia, como um todo, tem que estar enquadrada dentro das normas de Biossegurança, já que os profissionais dessa área atuam em hospitais, atendimentos domiciliares e ambulatoriais, nos quais há sempre contato físico com os seus pacientes. Assim, estes profissionais se tornam parte do grupo de risco de contaminação cruzada e o que se percebe é um descuido ou até mesmo um desconhecimento destes em relação a tais normas, por isso a urgência da propagação dos cuidados em Biossegurança.
\end{abstract}

Palavras-chave: Biossegurança. Contaminação. Fonoaudiologia. Saúde.

\begin{abstract}
Biosafety is of the utmost importance for any type of worker in carrying out their job. For health professionals, in addition to providing such a right to the patient, Biosafety conducts to eradicate the possible forms of cross-contamination during care. The objective of this work is to provide clarification on Biosafety in Speech Therapy, especially for professionals already working and to assist students in the field. The methodologies used were the literature review, in the Scielo, Lilacs and Google Scholar database, based on the Descriptors in Science and Health: biosafety, contamination, speech therapy and health. The inclusion criteria were articles that addressed the theme, in Portuguese, online, in full, published from 2007 to 2017. Speech therapy, as a whole, must be framed within the rules of Biosafety, since professionals in this area work in hospitals, home and outpatient care, where there is always physical contact with their patients. Thus, these professionals become part of the cross-contamination risk group and what is realized is a carelessness or even a lack of knowledge of the same regarding such standards, hence the urgency of the spread of care in Biosafety.
\end{abstract}

Keywords: Biosafety. Contamination. Speech therapy. Cheers.

\section{Introdução}

A Biossegurança é conceituada como a busca de prevenção de riscos patológicos e por isso, se torna desafiadora, além de aparentar enfadonha. Porém, suas regras são indispensáveis, principalmente, para profissionais que trabalham diretamente com a saúde (GUIMARÃES; BARBOSA, 2017).

O que se percebe entre os profissionais da saúde, inclusive aos fonoaudiólogos, é desconhecimento ou até mesmo uma desvalorização aos quesitos de Biossegurança, aumentando as possibilidades de infecção cruzada, que é uma forma de propagação de micro-organismos infecciosos. Com isso, este trabalho busca explanar sobre as informações imprescindíveis de Biossegurança, como forma de auxiliar na conscientização e ensino para profissionais e estudantes do curso de Bacharelado em Fonoaudiologia (FERNANDES et al., 2014).

O fonoaudiólogo é um profissional da saúde capacitado para atuar na promoção da saúde, prevenção, terapia (habilitação e reabilitação), avaliação e diagnóstico, orientação, e aperfeiçoamento dos aspectos fonoaudiológicos da função auditiva periférica e central, da função vestibular, da linguagem oral e escrita, da voz, da fluência, da articulação da fala e do sistema miofuncional, orofacial e de deglutição. É capacitado em exercer também atividade de ensino, pesquisa e administrativas. Além de poder trabalhar de forma autônoma nos setores público e privado (CFF, 2007).

Por mais que a Fonoaudiologia no Brasil tenha sido devidamente regulamentada na década de oitenta, sua história já é antiga e possui doze especialidades reconhecidas por seu conselho: Voz, Disfagia, Audiologia, Linguagem, Motricidade Orofacial, Saúde Coletiva, Gerontologia, Neuropsicologia, Fonoaudiologia Educacional, Neurofuncional, Fluência e Ocupacional. Por isso, pode atuar em Unidades Básicas de Saúde, ambulatórios de especialidades, hospitais e maternidades, consultórios, clínicas, home care, domicílios, asilos e casas de saúde, creches e berçários, escolas regulares e 
especiais, Instituições de Ensino Superior, empresas, veículos de comunicação (rádio, TV e teatro) e associações.

Em função dessa grande diversidade, é de extrema importância o conhecimento em Biossegurança, acompanhado de sua devida aplicação (CFF, 2007). Através desta se criou o Programa de Prevenção de Riscos Ambientais (PPRA), que é um conjunto de ações que visam preservação da integridade da saúde dos trabalhadores, através da antecipação, reconhecimento, avaliação e, assim, o controle da ocorrência de riscos ambientais existentes ou que venham a existir, considerando a proteção do meio ambiente e dos recursos naturais. Atualmente, é obrigatório por lei no Brasil, cada edifício deve conter as adequadas identificações dos riscos biológicos mais prováveis (ALBURQUERQUE, 2015).

O objetivo do presente trabalho foi proporcionar e esclarecer conhecimentos em Biossegurança na Fonoaudiologia, sobretudo, para profissionais já atuantes e para auxiliar estudantes da área.

\section{Desenvolvimento}

\subsection{Metodologia}

Neste estudo foi realizada uma revisão de literatura, na qual o referencial teórico foi construído através da localização e de seleção de estudos por meio de levantamento de textos publicados, nas interfaces de buscas Scientific Electronic Library Online (SciELO), Lilicas e Google Acadêmico. Para isso, foram utilizados os seguintes descritores, com base nos Descritores em Ciência e Saúde (DeCS), e suas combinações: fonoaudiologia, biossegurança, contaminação, saúde.

Os critérios de inclusão para os textos científicos foram: limitando-se a estudos em seres humanos, artigos referentes às áreas da saúde que abordassem a temática de Biossegurança na atuação da Fonoaudiologia, escritos no idioma português. Estes com acesso on-line, na íntegra, publicados e indexados nos referidos bancos de dados nos últimos dez anos (20072017), para acompanhar a evolução do assunto no meio acadêmico e salvaguardar o que há de mais atual e pertinente sobre o tema.

Os artigos foram organizados, em um banco de dados, para melhor análise descritiva das informações fornecidas. A amostra foi retirada de publicações de outras revisões literárias, estudos/relato de casos, trabalhos de conclusões de curso. Que possibilitou ler e classificar os dados para assim agrupar o máximo de conhecimento sobre o tema, que foi fornecido na revisão. Os trabalhos que não se enquadravam a esses parâmetros foram excluídos.

\subsection{Resultados}

Com base nos objetivos direcionais do estudo, foram selecionados treze arquivos, dispostos na integra e online. Em seguida, estes foram subdivididos em categorias, estudos de casos (em sua maioria pesquisas relacionadas com a vivência dos fonoaudiólogos com a Biossegurança) e manuais/roteiros sobre boas práticas em Biossegurança. Por meio desses, foi realizado um levantamento bibliográfico, e se viu que não há um trabalho que envolva aspectos gerais da Fonoaudiologia, por exemplo, com atuação audiológica e hospitalar no mesmo estudo. Por conseguinte, foi realizado este trabalho com enfoque em ressaltar o que há de mais pertinente e indispensável de Biossegurança para essa categoria (NASCIMENTO et al, 2014).

Com o exposto se compreendeu que a Biossegurança (BIO: vida + SEGURANÇA: sem perigo) é composta por um conjunto de normas que contribuem para a segurança no cotidiano, tentando prevenir o indivíduo de riscos físicos, ergonômicos, químicos, biológicos e psicológicos. Portanto, o fonoaudiólogo como a maioria dos profissionais da saúde, mais exposto a riscos biológicos, que são os que proporcionam infecção. As formas de contaminação podem ser de transmissão por contato (direto: transferência física direta; indireto: contato com objetos, como olivas e brinquedos; e perdigotos: gotículas emitidas por tosse, espirro ou conversa) e por veículo comum (transmissão aérea: gotículas ou sujeiras suspensas no ar e vetorial: animal ou inseto) (CFF, 2007). Por isso, enquanto atende seus pacientes, o fonoaudiólogo deve ter condutas básicas como: imunização, higienização das mãos, uso adequado de Equipamentos de Proteção Individual, manejo adequado de resíduos de serviços de saúde, processamento de superfícies e processamento de artigos, para o controle desse risco, independente do conhecimento da presença de doença infecto contagiosa em seu paciente (ROCHA et al, 2015).

\subsubsection{Vacinação}

Para a Biossegurança, a prevenção tem uma relevância maior do que o tratamento, a vacinação é um dos métodos utilizados para a prevenção e imunização de doenças virais ou bacterianas, que possam ser transmitidas entre pessoas. Sendo eficaz e segura, evita doenças graves ou complicações que podem até ocasionar a morte. Esse método é essencial para todos os profissionais da saúde, pois a maioria trabalha em contato físico com os seus pacientes, assim, há um constante risco para ambos. Já que o profissional, muitas vezes, não tem conhecimento sobre as patologias que o paciente carrega consigo e o paciente do seu profissional, com isso, é predeterminado que o profissional esteja em dia com alguns tipos de vacinas (ALBURQUERQUE, 2015).

A COVISA (Coordenação de Vigilância em Saúde) é o órgão responsável por defender e recomendar medidas para prevenção de doenças e promoção da saúde para a população. Determina que para esses profissionais é obrigatória a vacinação contra o Tétano, Difteria e Hepatite B, e para os que têm entre 20 a 59 anos de idade se imunizem contra Influenza, Varicela, Sarampo, Caxumba, Rubéola e Febre Amarela. Além disso, é exigido que todos portem seu histórico de vacina, de preferência atualizado (COVISA, 2019).

Os benefícios da imunização incluem proteção individual, 
interrupção da disseminação de doenças infecciosas de alguns surtos intra-hospitalares, além da proteção indireta de pessoas não vacinadas.

No entanto, se ocorrer algum contato com material biológico, é prudente fazer cuidados locais na área exposta imediatamente, como lavagem exaustiva com água e sabão em caso de exposição percutânea, uso de soluções antissépticas, mesmo se estiver com as vacinas em dia. Se houve exposição em mucosas é recomendada lavagem exaustiva com água e solução fisiológica. São contraindicados procedimentos que aumentam a área exposta (cortes, injeções locais), utilização de soluções irritantes como éter, hipoclorito ou glutaraldeído (MARQUES, 2017).

\subsubsection{Cuidados na avaliação}

A avaliação consiste no procedimento em que o fonoaudiólogo analisa, inicialmente, o paciente para identificar suas possíveis alterações nas estruturas responsáveis pela comunicação e/ou alimentação, como orelha e boca. A avaliação acontece por meio do contato do profissional com o paciente, diante disso é necessário tomar precauções, como o uso de EPI e lavagens de mãos, para que não ocorra algum tipo de contágio, por mais que os pacientes aparentem nenhuma doença infecciosa (SANTOS et al, 2014). Por meio dessa avaliação detalhada, os fonoaudiólogos devem saber como agir com cada paciente, qual tipo de luvas, máscaras, jaleco, artigos, tocas que irá utilizar. Por esse motivo há a necessidade de estudar detalhadamente as Normas Regulamentadoras (NR) de Biossegurança, nas quais se encontram explicações mais diretas de quais materiais devem ser utilizados com cada paciente, principalmente, quando este possui uma doença transmissível (EUGÊNIO et al., 2014).

\subsubsection{Ergometria}

A Biossegurança possui normas para a conservação da saúde do profissional, enquanto a disciplina do corpo (FERREIRA et al., 2017). Para ajudar o fonoaudiólogo a ter uma boa postura e a manipular o paciente, no âmbito hospitalar, corretamente, seguem algumas instruções:

$\checkmark$ A cadeira deve ser ajustável nos braços e na altura, para que o profissional possa ficar com as coxas na forma horizontal e consiga encostar os pés no chão. $\mathrm{O}$ encosto também deve ser regulável para suportar a parte inferior das costas (FERREIRA et al., 2017).A mesa deve ser ajustável.Durante o atendimento direto com o paciente, evitar torção de eixo vertical do corpo.Evitar inclinação do tronco e manter os membros inferiores inclinados.

$\checkmark$ Quando for preciso abaixar para realizar a fonoterapia é preciso fazê-lo com as costas inclinadas e os joelhos fletidos. Armazenar os artigos, os brinquedos em armários ou bancadas que não ultrapassem o nível da cabeça. Caso transpor este nível, utilizar bancos para o alcance.Realizar períodos de pausa entre os atendimentos.Evitar a realização de movimentos repetitivos

$\checkmark$ Realizar exercícios posturais, alongamentos, massagens para auxiliar na questão postural e exercícios vocais.

A relação da Fonoaudiologia com a ergonomia tem o ideal de garantir condições adequadas de trabalho e proporcionar maior expectativa de vida para o trabalhador (FERREIRA et al., 2017).

\subsubsection{Lavagem de mãos}

Uma medida de precaução padrão, que deve ser utilizada, exaustiva e cuidadosamente, por todos os profissionais na área da saúde, pois tem contato com diversas pessoas e objetos, assim está mais propício a entrar em contato com microorganismos infecciosos (CFF, 2007). A lavagem das mãos é essencial para a prevenção da saúde de qualquer pessoa, por isso é necessário realizá-la de maneira correta para que elimine qualquer agente infeccioso, esses são classificados em dois tipos: o Transitório (é aquele que permanece na pele por curto período de tempo) e o Residente (é aquele que fica mais profundo na pele e apresenta dificuldade de remoção e está menos relacionado com as infecções contagiosas) (GOMES et al., 2008).

Primeiramente, é preciso analisar onde lavar as mãos, pois o lavatório deve ser de uso exclusivo para isso e que dispense o uso das mãos para o fechar a torneira e o porta papel toalha deve evitar o mínimo contato possível com as mãos. Outro fator importante a ser observado é sobre os refis dos sabonetes, sendo indicado que esses sejam do tipo descartável, porque o reutilizado pode conter algum tipo de contaminação, e caso seja reutilizado, o recipiente deve ser bem higienizado com água e sabão e desinfetado com álcool etílico 70\% (CFF, 2007).

O fonoaudiólogo deve realizar a higiene de mãos corretamente a cada troca de paciente, antes de colocar as luvas, após o uso dessas e quando achar necessário. Isto por ter contato com objetos que podem estar infectados, como brinquedos, guias de língua, tubo de fonação, entre outros (ROCHA et al., 2015).

A higiene das mãos deve durar o período de 40 a 60 segundos, devendo-se retirar anéis, pulseiras e relógios e unhas sem esmalte ou com cores claras para ajudar na verificação de persistência de sujeiras. Segue a sequência de atos para alcançar melhor resultado (CFF, 2007):

1. abrir a torneira e molhar as mãos, evitando encostar na pia;

2. aplicar na palma da mão uma quantidade suficiente de sabonete líquido para cobrir todas as superfícies das mãos;

3. ensaboar as palmas das mãos, friccionando-as entre si;

4. esfregar a palma da mão contra o dorso uma da outra;

5. entrelaçar os dedos e friccionar os espaços interdigitais;

6. esfregar o dorso dos dedos de uma mão com a palma da mão oposta, segurando os dedos, com movimento de vai e vem;

7. esfregar o polegar direito, com o auxílio da palma da mão oposta, utilizando-se movimento circular;

8. friccionar as polpas digitais e unhas de uma mão contra a palma da outra, fazendo movimento circular;

9. esfregar um punho com auxílio da palma da outra mão, utilizando movimento circular;

10. enxaguar as mãos, retirando os resíduos de sabonete. Evitar contato direto das mãos ensaboadas com a torneira. O enxágue deve iniciar da ponta do dedo até os cotovelos;

11. secar as mãos com papel toalha descartável, iniciando pelas mãos e seguindo pelos punhos. No caso de torneiras com con- 
tato manual, feche utilizando o papel toalha.

Existem dois tipos de higiene das mãos, a lavagem com água e sabão (a mais recomendada) e a com antissépticos, que são de usos independentes e possuem as mesmas técnicas de fricção, porém com o álcool em gel se deve esperar secar naturalmente (GOMES et al., 2008).

\subsubsection{Estrutura do local}

A estrutura de clínicas deve seguir algumas recomendações para que esteja dentro dos padrões da vigilância sanitária (EUGÊNIO et al., 2014):

$\checkmark$ A sala de atendimento deve sempre estar em perfeitas condições higiênicas, ser bem arejada e, caso não seja, é recomendado o uso de ar condicionado que tenha manutenção anual (sendo necessário guardar o comprovante) não sendo recomendado o uso de ventilador, por facilitar a dispersão de micro-organismo no ar.O piso deve ser liso, resistente à lavagem e descontaminação e sem trincas, rachaduras e de preferência de cores claras. Teto e paredes sejam de cor clara, material liso e resistente à lavagem e sem rachaduras e umidades.Iluminação natural ou/e artificial suficiente e em bom estado de conservação.

$\checkmark$ Bancada deve ser de material de fácil limpeza e descontaminação e com pontas se não arredondadas com proteção.

$\checkmark$ Duas pias por consultório, uma para a lavagem de mãos e outra para desinfecção. Nas pias, as torneiras devem conter água potável, corrente e ligada à rede pública.Coletor de lixo com tampa e pedal.Toalheiro de papel e o dispensador de sabonete líquido, na pia destinada para lavagem das mãos.Presença de extintor de incêndio de fácil acesso.Esterilização em uma sala específica.Espelho com moldura, pontas arredondadas e em perfeitas condições.As salas de audiometria devem ter isolamento acústico (piso, parede, janela) com espuma acústica, placas acústicas e tem que ter o comprovante de que realiza a reabsorção das ondas sonoras.É importante ter um local para

armazenar alimentos e objetos pessoais.

\subsubsection{Limpeza}

No ambiente se deve realizar a limpeza de manutenção, que é feita com pano limpo e umedecido de água e sabão, em computadores, estantes, armação de macas e mesas. Se houver sujidade ou matéria orgânica é preciso fazer remoção mecânica (CFF, 2007).

Em caso de ocorrência de vômito no local, que comumente ocorre nas clínicas de reabilitação labiríntica, a matéria orgânica deverá ser depositada no piso ou ser jogada em um recipiente (a vasilha deve estar sempre presente no local e de preferência ser descartável), e as etapas da limpeza e desinfecção devem ser: retirar a matéria orgânica com pano ou papel toalha, realizar limpeza do local com água e sabão, enxaguar, espera secar e aplicar o desinfetante (ALBURQUEQUE et al., 2015).

A manutenção do ambiente de trabalho é importante não apenas pela Biossegurança, mas também ajuda o ambiente a ser mais agradável tanto para o profissional como para o paciente.

\subsubsection{Equipamentos de proteção individual (EPI)}

Para a Biossegurança é indispensável citar os EPI, acessórios ou produtos de uso individual utilizado pelo trabalhador, que têm por finalidade protegê-lo de riscos ou ameaças à segurança e à saúde (ROCHA et al., 2015).

Os EPI são classificados de acordo com a área e a função que o indivíduo vai realizar. Os mais utilizados na área da saúde, em especial entre os fonoaudiólogos, são:

$\checkmark$ Aventais: servem de barreira de proteção para as roupas pessoais devendo ter colarinho alto, punhos ajustáveis e mangas longas e sempre mantidos abotoados. Deverá ser utilizado, exclusivamente, para o atendimento ao paciente infectado no ambiente hospitalar, ou com risco de emissões secretivas, como na reabilitação e/ou avaliação da disfagia, a fim de evitar veiculação de micro-organismos.

$\checkmark$ Jalecos: para facilitar a visualização de sujeiras é bom que seja branco, sendo adequado que sejam trocados diariamente, ou sempre que contaminados por fluídos corpóreos. Não se deve sentar sobre bancadas e pias com esse vestido, além de ter o cuidado de não encostar em paredes ou em outros locais prováveis de contaminação. Deve ser retirado ainda no local de trabalho e colocado em sacos de plástico para limpeza (lembrando de lavar separado das demais roupas) ou descarte (EUGÊNIO et al, 2014).

$\checkmark$ Máscaras: são indicadas como barreiras das vias áreas superiores, o seu uso deve seguir os princípios de conforto e adaptação, a sua troca deve ocorrer a cada atendimento e quando estiver molhada ou suja, são comumente usadas nas avaliações/ reabilitações de Órgãos Fonoarticulatórios (OFAS). É contraindicado permanecer com a máscara ao redor do pescoço, deve ser retirada ou deixar pendurada em uma orelha. Nunca saindo da sala de atendimento com esta (CFF, 2007).Luvas: evita o contato com líquidos corporais, secreções e objetos contaminados, como na realização de meatocopia, manipulação dos OFAS, higienização de olivas e materiais possivelmente contaminados. As luvas de procedimento (de látex, descartáveis) devem ser trocadas imediatamente após cada atendimento e sempre que ocorrerem furos (CFF, 2007). Quando estiver com as mãos enluvadas não se deve manipular objetos fora do campo de trabalho (canetas, fichas clínicas, maçanetas, telefone, etc.), vale ressaltar que o uso de luvas não exclui a lavagem das mãos antes e logo que forem retiradas. As luvas são artigos descartáveis e não devem ser reutilizadas, lavadas (lavagem de mãos enluvadas), desinfectadas ou esterilizadas e o descarte deve ser feito em lixo apropriado para material infectante.

$\checkmark$ Toucas: esse instrumento é mais utilizado pelos fonoaudiólogos nas terapias de motricidade orofacial, no âmbito de intervenção precoce (Clínica) e hospitalar (principalmente, em Unidade de Terapia Intensiva) na qual o profissional deve estar com o gorro ou touca para que os cabelos não atrapalhem os exercícios a serem realizados e para que não respingue gotículas de substâncias corpóreas neste (CFF, 2007).

$\checkmark$ Óculos de proteção: são indicados para todos os procedimentos que possam envolver exposição a gotículas de saliva, como na avaliação das estruturas relacionadas com a comunicação e/ou deglutição. Devem ter proteção lateral, oferecer conforto, com bom ajuste ao rosto do profissional e por ser um artigo reutilizável deve ser submetido à limpeza. Os óculos corretivos não substituem o uso destes (CFF, 2007).

Relevante ressaltar que resíduos com possível presença de agentes biológicos, que são comumente utilizados na avaliação/terapia da motricidade orofacial, disfagia, linguagem, voz, ou na avaliação audiológica e/ou labiríntica, devem ser descartados em sacos branco-leitosos, identificados com símbolo de substância infectante, com desenho e contornos pretos que devem ser substituídos quando atingirem dois terços de sua capacidade ou a cada 24 horas. Devem ser levados por empresas especializadas em incineração (CFF, 
2007).

\subsubsection{Instrumentos de trabalho dos fonoaudiólogos}

$\mathrm{Na}$ área da saúde, os cuidados com a esterilização ou desinfecção de superfícies e objetos são extremamente relevantes no controle de infecção, os métodos mais eficazes seriam usar utensílios recicláveis, no caso de cubas e olivas, havendo o descarte adequado após o uso ou utilizar objetos do próprio paciente, como escovas de dente no lugar de espátulas, este último ganha destaque por ser uma forma de diminuir a produção de lixo (SPERI et al, 2017). Quando não houver essas possibilidades, a maneira como proceder com um objeto para reutilização entre pacientes vai depender do potencial de risco de aquisição infecciosa pela reutilização desse, se será necessário o processo de desinfecção ou de esterilização, devendo ser feitos a cada troca de paciente. Antes da ocorrência desses processos, deve-se passar pela limpeza do objeto, que consiste na remoção de sujidade para assim garantir a eficácia da desinfecção ou esterilização, sendo essa realizada com água e detergente (GOMES et al., 2008).

Artigos críticos: são os que penetram tecidos estéreis ou sistema vascular e devem passar por uma esterilização, que é um processo que utiliza agentes químicos ou físicos ou, ainda, associação desses para destruir todas as formas de vida microbiana, sendo aplicada somente em objetos, não sendo possível em superfícies, como mesas e pisos. É feita através da imersão por até 10 horas em glutaraldeídeo $2 \%$ (solução ácida), que depois de ativada por alcalinizantes, mantém sua atividade por 14 ou 48 dias, tendo que ser monitorada com fitas marcadoras específicas, pois ao perceber qualquer mudança a solução deve ser trocada. Essa imersão ocorre em um recipiente plástico com tampa, para evitar o desconforto respiratório causado por possíveis vapores. O enxágue deve ser realizado com água e a secagem em compressa pela técnica asséptica, o que requer paramentação, tudo isso estéril. Não esquecendo de sempre usar luvas e máscaras para vapores químicos ao manipular a solução. A esterilização mais eficaz é por meio da autoclave, porém, na Fonoaudiologia, esse método se torna inviável para muitos artigos que são sensíveis ao calor, por isso a escolha do glutaraldeídeo $2 \%$, já que este não danifica plástico, metal, borracha, vidro ou silicone, mas pode haver corrosão eletrolítica quando houver mistura com diferentes metais. Na Fonoaudiologia é recomendada a esterilização para toda vez que um objeto entrar em contato com sangue, leite materno, muco (secreção da boca, nariz, ouvido) ou cerume, este último é considerado infeccioso, quando entra em contato com sangue, mas sua cor e consistência dificultam essa discriminação visualmente, por isso deve sem ser considerada substância infecciosa. Artigos semicríticos: entram em contato com a pele ou com mucosas e requerem esterilização ou a desinfecção, este é o procedimento que inativa os micro-organismos na forma vegetativa, sendo realizada com hipoclorito de sódio $1 \%$ por imersão de 30 minutos seguido de enxágue e álcool 70\% aplicado sob fricção, deixando-o secar e repetindo três vezes isto. Exemplo: equipamentos respiratórios de anestesia, guia de língua, aparelhos auditivos, fones de ouvido, material pra mioterapia, brinquedos (na escolha optar que sejam de um material lavável, como plástico) e outros objetos utilizados na prática fonoaudiológica. Os objetos que entraram em contato com a boca ou ouvido devem ser manuseados com luva até serem desinfetados.Artigos não críticos: requerem desinfecção ou limpeza. Exemplo: aparelhos para medir pressão arterial, oxímetro, diapasão, estetoscópio, eletrodos, cuba, cânula para irrigação.

Os critérios para escolha de produtos químicos devem ser considerados como: registro no Ministério da Saúde; indicação de uso do produto (artigos, superfícies e de equipamento ambiente); espectro de ação; tempo de ação; risco envolvido para o trabalhador, e as medidas de Biossegurança e custo.

Após a esterilização ou desinfecção, os objetos devem ser guardados adequadamente em um lugar limpo, protegido do meio externo e em vasilhas usadas exclusivamente para isso, evitando uma possível contaminação, como as olivas e espéculos limpos que devem ser guardadas em potes com tampa e, se possível, com data de desinfecção e sempre devem ser manuseadas com luvas, como forma de erradicar infecção cruzada. Com as gazes e demais materiais descartáveis também se deve proceder da mesma forma, lembrando sempre de deixar todos os recipientes tampados (principalmente, durante os atendimentos) e que devem ser desprezados em saco de lixo branco leitoso, com símbolo de infectante. E com as macas, usadas em clínicas audiométricas, deve-se ter o cuidado de trocar os lençóis ou cobrir com papel, fazendo sempre a limpeza com gaze embebecida em álcool $70 \%$, friccionando durante 30 segundos após cada atendimento, sendo preciso que sejam revestidas com material impermeável a água (CFF, 2007).

\section{Conclusão}

Após a leitura dos artigos científicos, percebeu-se que entre alguns fonoaudiólogos, há um alarmante índice de desconhecimento ou desvalorização quando se trata do assunto de Biossegurança, sendo assim um fator agravante para propagar possíveis riscos de infecção. O principal motivo para tal ocorrência é uma carência no ensino e aprendizado desse assunto, no meio acadêmico, e isso reflete nos muitos fonoaudiólogos e demais profissionais da saúde quanto a esse quesito. Foi percebida, também, uma falta de campanhas que proporcionem conscientização entre os profissionais da saúde para um reforço das principais normas de Biossegurança.

Com a falta de um trabalho científico que abrangesse diversas áreas da Fonoaudiologia e que perpassasse aos quesitos fundamentais da Biossegurança, alcançou-se o objetivo do estudo, no qual se buscou reunir o máximo de prática em Biossegurança, com ênfase na Fonoaudiologia, 
para oferecer um maior conhecimento das medidas de controle de infecção, acimas citadas. Com a finalidade de haver uma melhora nos atendimentos, já que esses profissionais da saúde devem atuar também na prevenção e no controle de infecções pessoais e dos pacientes, assim contribuindo para a saúde coletiva e meio ambiente.

\section{Referências}

ALBURQUERQUE, M.A. et al. Biossegurança em Fonoaudiologia. Rev. CEFAC, v.17, 2015.

CFF - Conselho Federal de Fonoaudiologia. Medidas de Controle de Infecção para Fonoaudiólogos - Manual de Biossegurança. Brasília: CFF, 2007.

COVISA. Vacinação. Disponível em: <https://www.prefeitura. sp.gov.br/cidade/secretarias/saude/vigilancia_em_saude/ doencas_e agravos/index.php?p=7309> Acesso em: 5 jul. 2019.

EUGÊNIO, M.L.et al. Condutas de biossegurança em ambulatório de fonoaudiologia da rede SUS. Rev. Distúr. Comum., v.26, n.1, p.42-49, 2014.

FERNANDES, C.G. et al. Biossegurança aplicada à motricidade orofacial. Manual de motricidade Orofacial, 2014.

FERREIRA, N.L. et al. Em direção a uma universidade saudável: manual sobre ergonomia. Disponível em: http://www.dgrh. unicamp.br/documetos/manuais/man_dsso_ergonomia.pdf> Acesso em: 30 set. 2019.

GOMES, A.M. et al. Medidas de biossegurança em audiologia. Rev. CEFAC, v.10, n.4, p.603-610, 2008.

GUIMARÃES, V.C.; BARBOSA, M.A. Riscos ocupacionais em fonoaudiólogos de uma unidade hospitalar: um estudo-piloto. Distúrb. Comun, v.19, n.3,2007.

NASCIMENTO, E.N. et al. Acompanhamentos fonoaudiólogos do idoso e biossegurança. Disponível em: $<$ https://ares.unasus. gov.br/acervo/handle/ARES/1442>. Acesso em: 5 set. 2019.

PREFEITURA DO RIO DE JANEIRO. Roteiro de inspeção dos estabelecimentos de fonoaudiologia. Disponível em: $<\mathrm{http}: / /$ www.rio.rj.gov.br/dlstatic/10112/5133026/4132818/roteiro_ fono.pdf>. Acesso em: 18 out. 2019.

ROCHA, A.P.F. et al. Medidas de biossegurança adotadas por profissionais atuantes em audiologia. Rev. CEFAC, v.17, n.1, p.96-106, 2015.

SANTOS, J.N. et al. Condutas de biossegurança em ambulatório de fonoaudiologia da rede SUS. Distúrb. Comun, v.26, n.1, 2014.

SPERI, M. R. et al. Recursos de biossegurança na avaliação audiológica básica: estudo comparativo entre o uso do protetor descartável de fone de ouvido e o uso do policloreto de vinila (PVC). Distúrb. Comum, v.29, n.2, p.292-301, 2017. 